\title{
Eliasz Cynamon e o Programa do Rio Doce (Sesp): contribuição de fontes para a história das ações de saúde e saneamento no Brasil, 1952-1960
}

\author{
Eliasz Cynamon and the Rio Doce Program (SESP): \\ contribution of sources to the history of health \\ and sanitation actions in Brazil, 1952-1960
}

\section{Renato Gama-Rosa Costa \\ Pesquisador e professor, Casa de Oswaldo Cruz/Fiocruz. \\ Rio de Janeiro - RJ - Brasil \\ renato.gamarosa@fiocruz.br}

\section{Simone Cynamon Cohen}

Pesquisadora e professora, Escola Nacional de Saúde Pública Sergio Arouca/Fiocruz.

Rio de Janeiro - RJ - Brasil

cohen@ensp.fiocruz.br

\section{Camila Nunes Soterio \\ Bolsista, Casa de Oswaldo Cruz/ Fiocruz. \\ Rio de Janeiro - RJ - Brasil \\ camilan.soterio@gmail.com}

Recebido para publicação em 23.01.2017.

Aprovado para publicação em 06.06.2017.
COSTA, Renato Gama-Rosa; COHEN, Simone Cynamon; SOTERIO, Camila Nunes. Eliasz Cynamon e o Programa do Rio Doce (Sesp): contribuição de fontes para a história das ações de saúde e saneamento no Brasil, 19521960. História, Ciências, Saúde - Manguinhos, Rio de Janeiro, v.25, n.1, jan.mar. 2018, p.245-259.

\section{Resumo}

Apresenta pesquisa acerca da atuação de Szachna Eliasz Cynamon no Programa Vale do Rio Doce (1952-1960). Privilegiamos como fonte de consulta os acervos dos departamentos de Arquivo e Documentação e de Saneamento e Saúde Ambiental, na Fiocruz, e o ainda pertencente à família. Na época, a região contava com altos índices de malária. Cynamon, nascido na Polônia e imigrado ainda criança nos anos 1930 para o Brasil, onde se graduaria em engenharia sanitária, foi contratado para atuar em Colatina (ES) e em Governador Valadares (MG), entre 1952 e 1960. Nessas localidades, dedicou-se ao tratamento e abastecimento de água e esgoto sanitário, além de realizar cursos de educação sanitária para a população local, como parte de acordo de cooperação Brasil-EUA.

Palavras-chave: Szachna Eliasz Cynamon (1925-2007); Programa do Rio Doce; Serviço Especial de Saúde Pública; saneamento ambiental; acervo.

\section{Abstract}

Research into the work of Szachna Eliasz Cynamon in the Rio Doce Valley Program (1952-1960) is presented. The key sources are from the Department of Archives and Documentation and the Department of Sanitation and Environmental Health at Fiocruz, as well as the family's own archive. At the time, the rates of malaria in the region were high. Born in Poland, Cynamon migrated to Brazil in the 1930s while still a child, where he graduated in sanitary engineering. He was hired to work in Colatina (Espírito Santo) and Governador Valadares (Minas Gerais) between 1952 and 1960, focusing on sewage and water treatment and supply, while also holding sanitation education courses for the local people as part of a Brazil-USA cooperation agreement.

Keywords: Szachna Eliasz Cynamon (1925-2007); Rio Doce Program; Special Public Health Service; environmental sanitation; archive. 
Cachna Eliasz Cynamon (1925-2007) foi o criador, em 1965, do Departamento de Saneamento e Saúde Ambiental (DSSA) da Escola Nacional de Saúde Pública Sergio Arouca (Ensp), unidade técnico-científica da Fundação Oswaldo Cruz (Fiocruz). Antes de integrar o DSSA, atuou como engenheiro sanitarista no Serviço Especial de Saúde Pública (Sesp) de 1952 até a sua ida para a Ensp. Cynamon foi contratado pelo Sesp para trabalhar no Programa "do Rio Doce", região que registrava altos índices de varíola, febre tifoide, malária e parasitoses. Inicialmente foi admitido como engenheiro distrital no Centro de Saúde do Sesp em Colatina, Espírito Santo, região de extração mineral de mica, ferro e pedras preciosas. Entre 1952 e 1954 trabalhou no município mineiro de Governador Valadares, região de produção de aço e ferro-gusa. Nesses anos, e esse será especialmente o foco de parte de nossas pesquisas, Cynamon trabalhou em obras para instalações de tratamento e abastecimento de água e esgoto sanitário em pequenos municípios, além de realizar cursos de educação sanitária para a população local.

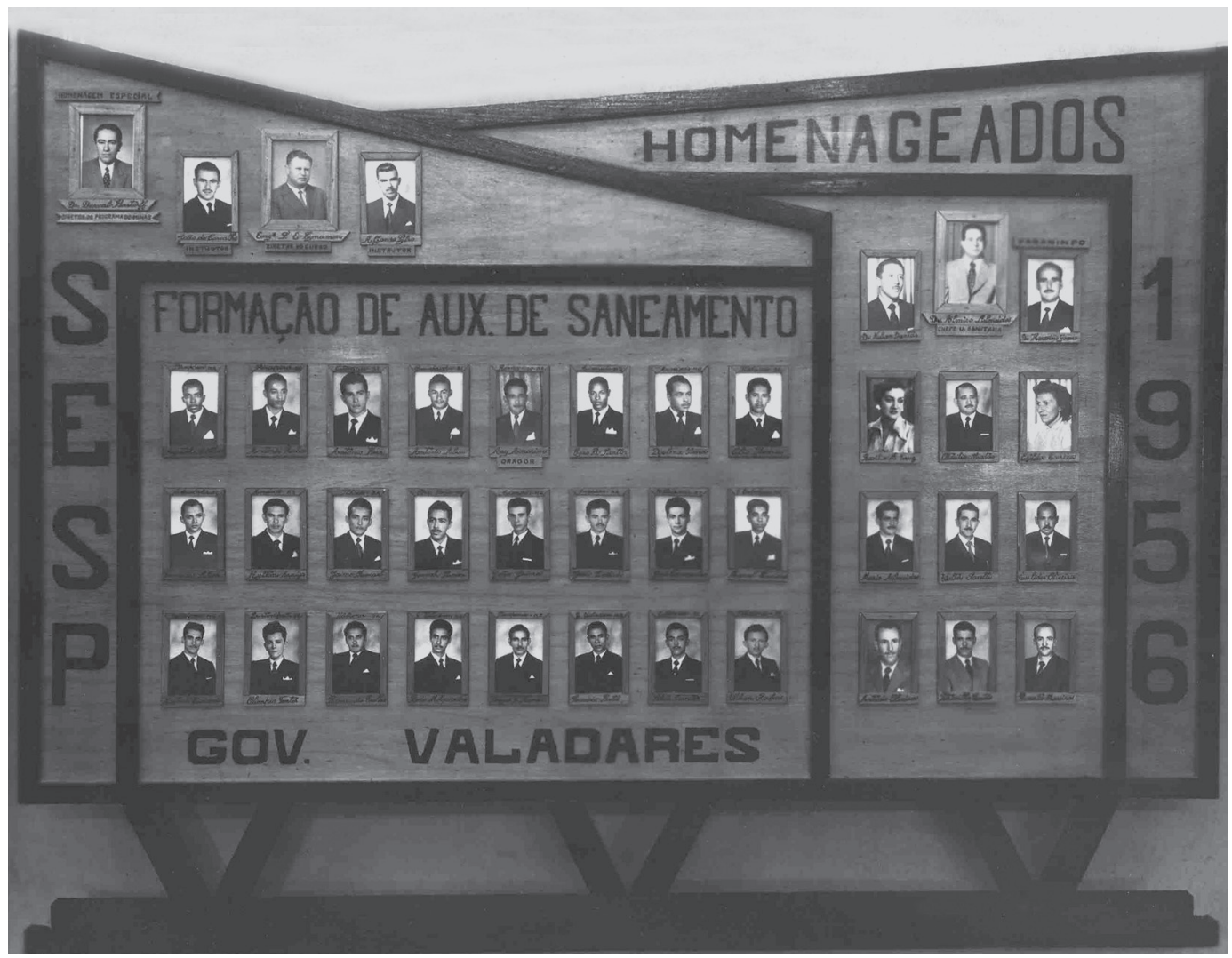

Figura 1: Curso de formação de auxiliares de saneamento para a cidade de Governador Valadares pelo Sesp, 1956 (Acervo pessoal da família Cynamon)

O acervo pessoal de Cynamon, bem como do Sesp, encontra-se no Departamento de Arquivo e Documentação (DAD) da Casa de Oswaldo Cruz da Fiocruz. Uma parte do acervo pessoal do sanitarista está sob a guarda do DSSA, na Esnp, e também ainda 


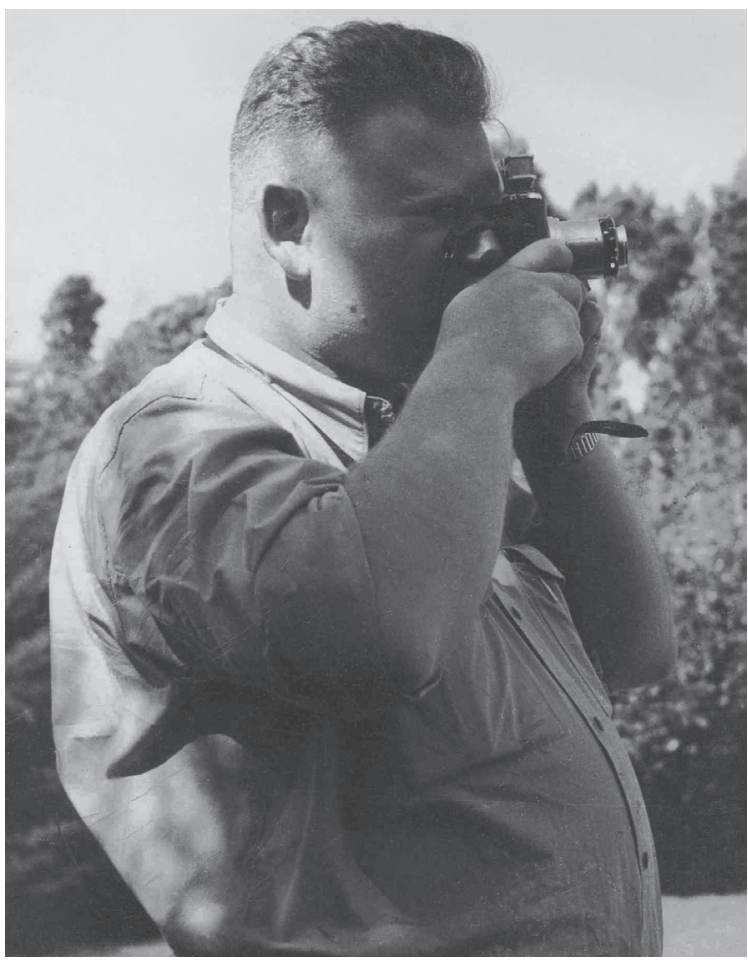

Figura 2: Cynamon em trabalho de campo, s.d. (Acervo pessoal da família Cynamon) com a família, sobretudo fotos e slides da época em que ministrava aulas de saneamento em vários locais no Brasil e em alguns países da América Latina e Europa e demais aspectos acerca de sua vida pessoal e profissional. Esses acervos serão privilegiados nesta linha de pesquisa, contribuindo para a divulgação de sua importância na institucionalização do ensino da engenharia sanitária e do saneamento ambiental no Brasil, especialmente nos anos 1950 e 1960, por meio do Programa do Rio Doce. Dos acervos consultados destacaremos em particular o Manual para o guarda sanitário (Póvoa Filho, s.d.) e o Manual de saneamento (Brasil, 1964), além de fotos de sua atuação profissional nas localidades estudadas por nós. Esperamos, assim, contribuir para o entendimento e a reflexão acerca de um projeto importante em sua época, mas que ainda se mostra de extrema necessidade, haja vista os recentes acontecimentos e surtos de febre amarela na região.
O investimento em municípios pelo interior brasileiro iniciou-se timidamente há menos de cem anos. A denominada "era do saneamento" teve início após a constatação de Miguel Pereira (citado em Hochman, 2013, p.88), em 1916, de que "de fato, o Brasil [era] um vasto hospital". Nos últimos anos da década de 1910, algumas iniciativas indicavam que ações nas cidades pelo interior brasileiro eram necessárias para combater doenças associadas à falta de higiene e à segurança sanitária nas residências do trabalhador e suas famílias. Os serviços sanitários nos níveis municipal, estadual e federal constataram que as doenças que atingiam a população brasileira não eram um fenômeno, e sim uma realidade, desencadeando uma série de ações de saneamento pelo interior do país. A indicação era de que o governo federal deveria se responsabilizar por estruturar um único órgão com capacidade de planejar e gerenciar, no nível nacional, as questões referentes à saúde pública, o que foi feito com a criação do Departamento Nacional de Saúde Pública (DNSP) em 1918 e depois, em 1930, com a institucionalização do Ministério da Educação e Saúde Pública (MES) (Snis, 2016).

Por outro lado, a presença da Fundação Rockefeller nas Américas ou mesmo em outros continentes desempenharia um papel relevante em termos de saúde pública, até a criação da Organização Mundial da Saúde (OMS), em 1948 (Campos, 2006). As duas grandes guerras (1914-1918 e 1939-1945) "também incitaram a assinatura de acordos, entre governos, para planejamento e execução de políticas de saúde internacionais”, incluindo o do Brasil (p.35). 
Foi nesse contexto que foi criado, em 1942, o Serviço Especial de Saúde Pública (Sesp), num acordo bilateral Brasil-EUA, em que a exploração de ferro e de outros minérios e da borracha teria, como contrapartida, a instalação de serviços de saneamento e de saúde pública em cidades do interior do Brasil. O órgão, do qual o cientista Eliasz Cynamon foi funcionário, atuando como engenheiro sanitário por todo o Brasil, será o objeto de análise deste artigo. Estudaremos particularmente sua atuação nos estados de Minas Gerais e Espírito Santo, por meio do Programa do Rio Doce, mais precisamente nas cidades de Governador Valadares (MG), Aimorés (MG) e Colatina (ES).

Curiosamente, o minério de ferro que contribuiria para ações de saneamento e saúde pública na região do Vale do Rio Doce há cerca de setenta anos é o mesmo cuja exploração recente originou um dos maiores desastres ambientais de nossa história. Em 5 de novembro de 2015, o rompimento da barragem da mineradora Samarco causou a destruição do distrito de Bento Rodrigues, município de Mariana (MG), situado às margens do rio Doce. O rompimento liberou 62 milhões de rejeitos de mineração, causando uma enxurrada de lama tóxica, constituída principalmente de óxido de ferro. O desastre ambiental pode afetar os ecossistemas, por conta da destruição da composição química do solo atingido pela lama. Esse fato possivelmente impedirá o desenvolvimento de inúmeras espécies vegetais, tornando a região infértil e provocando a extinção total do ambiente que existia antes do acidente (Santos, 2015). Outra consequência possível, e que vem mostrando sua face mais cruel um ano após o desastre, é o surto de febre amarela confirmado em janeiro de 2017 nas cidades localizadas ao longo do rio Doce e atingidas pelo rompimento da barragem do Fundão. ${ }^{1}$

\section{A constituição do Serviço Especial de Saúde Pública e o acordo com o Instituto de Assuntos Interamericanos}

O Sesp foi criado em 17 de julho de 1942, em respeito às decisões deliberadas no terceiro Encontro de Ministros das Relações Exteriores das Repúblicas Americanas, realizado no Rio de Janeiro, em que foram assinados os chamados Acordos de Washington. Por esse acordo, os governos brasileiro e norte-americano atenderiam a urgências de uma diplomacia de guerra e à organização de uma agência bilateral de saúde pública. Essa agência precisava atender a ações que visavam dar proteção aos soldados americanos enviados para atuar nas bases militares no Brasil, em relação às chamadas doenças tropicais, e mesmo aos trabalhadores brasileiros que precisavam se proteger contra a malária e outras doenças infecciosas, enquanto o Brasil deveria fornecer borracha, ferro e outras matérias-primas para as ações de guerra (Campos, 2006). O Sesp se divide historicamente em dois períodos, entre 1942 e 1945, em que primeiramente serviu aos interesses militares norte-americanos no Brasil; e entre 1946 e 1960, quando se concentrou nos projetos de caráter desenvolvimentista do Estado brasileiro (Funasa, 2004; Melo, 2004; Monteiro, 2015).

Para atender ao acordo firmado visando à criação do Sesp, foram estabelecidas duas estratégias principais por meio de um contrato básico. Competia ao Sesp empreender ações de saneamento, primeiramente no vale amazônico, objetivando facilitar o controle da malária, por meio de assistência médica aos trabalhadores da extração da borracha. Por 
conta da exploração do ferro e de outros minérios, como a mica, o Sesp atuaria depois no saneamento de outras regiões brasileiras, sobretudo no interior de Minas Gerais e Espírito Santo, procurando garantir igualmente condições básicas de saúde de tais regiões. No vale do rio Doce, o Sesp agiria na profilaxia e nos estudos da malária e, também, na assistência médico-sanitária a trabalhadores e moradores da região na reconstrução da Estrada de Ferro Vitória-Minas.

A segunda estratégia dizia respeito ao preparo de profissionais para o trabalho de saúde pública, compreendendo o aperfeiçoamento de médicos e engenheiros sanitaristas, a formação de enfermeiras de saúde pública e a realização de cursos técnicos (Bastos, 1993). Tais profissionais eram selecionados para atuar como agentes de educação sanitária, em atendimento hospitalar e na construção de instalações básicas de esgotamento sanitário e abastecimento de água. Foi nessas condições que Cynamon iniciou suas atividades profissionais, ainda muito jovem.

As ações foram instituídas, pela parte brasileira, por intermédio do Sesp, subordinado ao Ministério da Educação e Saúde, e, pela parte norte-americana, por meio do Instituto de Assuntos Interamericanos (Iaia), cuja criação foi aprovada em 30 de março de 1942. O Iaia estava subordinado ao Escritório do Coordenador de Assuntos Interamericanos, "destinado a coordenar e administrar os programas bilaterais de saúde na América Latina e outros" (Bastos, 1993, p.27). Por sua vez, teria a tarefa de "defender a saúde dos homens que precisavam de saúde para poder produzir, de homens que necessitavam de saúde para se tornarem capazes de fornecer aos arsenais da democracia o material necessário para a luta em defesa do bem-estar dos povos" (p.30-31).

\section{O Programa do Rio Doce}

Em setembro de 1942, seria concebido o Programa do Rio Doce, depois de uma viagem de inspeção feita à área, por representantes do Iaia, do Sesp e dos departamentos de saúde dos estados de Minas Gerais e Espírito Santo. "O contrato seria assinado em 10 de fevereiro de 1943, prevendo, então, execução de medidas de saúde e saneamento no vale do Rio Doce" (Bastos, 1993, p.107). O contrato previa atuação nas principais cidades do vale, atingidas por uma forte epidemia de malária, sobretudo em Governador Valadares, nas demais cidades localizadas ao longo do percurso da Estrada de Ferro Vitória-Minas e nos acampamentos dos trabalhadores empregados na construção da ferrovia (Bastos, 1993).

As atividades a desenvolver no programa chamavam a atenção, segundo o relatório do programa de 1944, para uma região: "praticamente virgem no que se refere a um verdadeiro programa de saúde pública" (PRD, 1944, p.164). Para tentar reverter tal quadro, as estratégias agiriam em duas frentes - nos acampamentos onde trabalhadores reconstruíam a Estrada de Ferro Vitória-Minas, responsável por transportar matéria-prima (ferro, mica e borracha), entre as das atividades econômicas previstas no acordo com os EUA, e nas vilas e cidades localizadas em áreas endêmicas da região do vale do rio. Nessas frentes, as ações se davam por meio da realização de inquéritos sobre as doenças locais, no controle do principal mosquito transmissor e na instalação de postos, unidades de saúde e mesmo hospitais de pequeno porte e clínicas para tratamento de moléstias como malária e pa- 
rasitoses intestinais. Estavam previstas, igualmente, intervenções diretas nas residências dos trabalhadores da ferrovia e da população local, procurando promover melhorias no padrão das moradias existentes. Tais ações se integravam às de instalação de sistemas de esgoto, bem como ao desenvolvimento e distribuição de abastecimento geral de "água livre de contaminação" nas três principais cidades do vale: Governador Valadares, Colatina e Aimorés. Não menos importante, o documento destacava as ações educativas, em que objetivava incutir na população local o valor de uma boa saúde, "ensinando ao mesmo tempo os meios de obtê-la e preservá-la" (PRD, 1944, p.164).

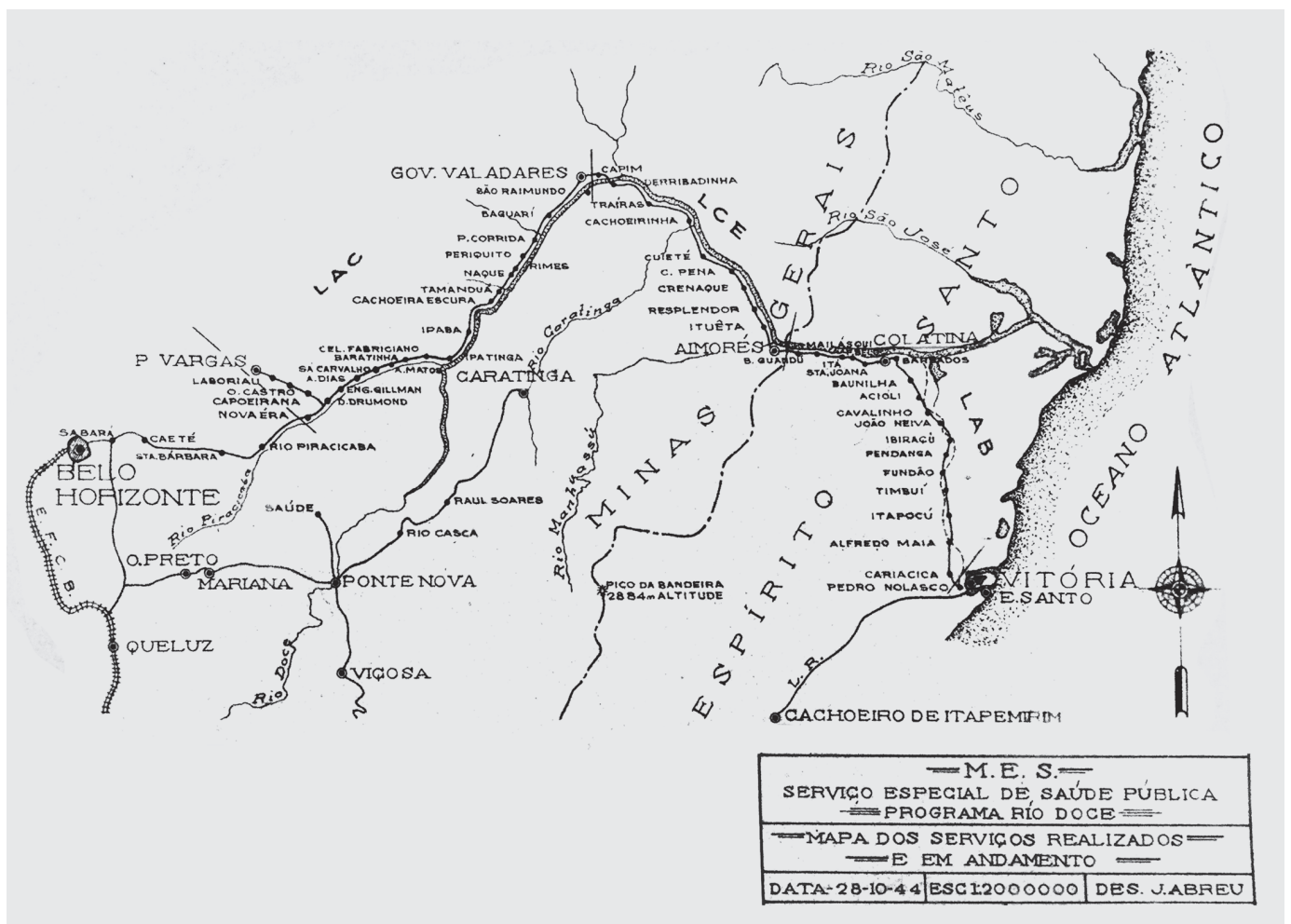

Figura 3: Mapa do Programa do Rio Doce, 1947 (Fundo Sesp; dossiê, A-00-OF-116, p.394. DAD/COC/Fiocruz)

Segundo relato de Brito Bastos (1993, p.108), que atuou como médico para o Sesp, o primeiro ano de trabalho do Programa do Rio Doce foi muito difícil, principalmente devido "à falta de pessoal devidamente capacitado para as funções administrativas e técnicas, nos escritórios ... e na operação e manutenção dos trabalhos". A contratação do jovem Szachna Eliasz Cynamon, assim como ocorreria com outros, beneficiou-se da necessidade de se ter profissionais capacitados para atuar no programa. Sua participação se daria de forma expressiva nas ações de saneamento, tanto na parte técnica como administrativa e educacional, como veremos. 


\section{A atuação do engenheiro Cynamon}

A família de Cynamon chegou ao Brasil no dia 5 de fevereiro de 1933, acompanhada de muitos judeus poloneses que haviam escolhido morar no Brasil, fugindo da deterioração econômica em que se encontrava a Europa e da ascensão do nazismo. Como bem lembrou Eliasz, em entrevista a Casa de Oswaldo Cruz, Hitler estava na iminência de assumir o poder, quando a família embarcou para o Rio de Janeiro, primeiramente para Petrópolis (Cynamon, 3 fev. 2004, fita 1, lado A). Concluiu seus estudos no Rio de Janeiro e começou a cursar engenharia civil na então Universidade do Brasil, atual Universidade Federal do Rio de Janeiro. Em 1950, durante estágio no escritório de um de seus professores na época, o engenheiro Greg Zaharov, foi por ele aconselhado a procurar participar dos projetos do Sesp pelo interior do Brasil "para adquirir experiências de campo e de vida" (Tércio, 2011, p.17). Em abril de 1952, Cynamon foi aprovado para um estágio no Sesp relacionado ao processo de implantação de saneamento básico em Colatina (ES), que possuía um dos maiores centros de saúde do Sesp. O Centro de Saúde de Colatina realizava serviços de estatística, higiene materna e infantil, assistência médica, visitação domiciliar de educação higiênica, controle de doenças venéreas, controle de estabelecimentos de gêneros alimentícios, além de ações em saneamento, atuação em escolas e atendimento hospitalar, com capacidade para sessenta leitos, o que tornava a cidade referência em saúde na região, abrangendo os municípios vizinhos de Linhares, Ipiraçu, Colatina e Baixo Guandu (Cynamon, 3 fev. 2004).

Ao completar dois meses de estágio nessa cidade, Cynamon foi efetivado como engenheiro sanitarista, no cargo de inspetor de saneamento, sendo designado para trabalhar em Governador Valadares (MG) e Aimorés (ES), no Programa do Rio Doce (Tércio, 2011), que na época já completava uma década de atividade. Por sua vez, o Sesp, a essa altura, já atuava na estratégia de atender a projetos de caráter desenvolvimentista para o Estado brasileiro (1946-1960).

A realidade encontrada por Cynamon mostrava casas sem infraestrutura adequada, em "sapê e teto de folhas de palmeira" (Knott citado em Campos, 2006, p.175-176). A descrição feita pelo médico James Knott, diretor americano do Programa Rio Doce, em seu relatório acerca do projeto, em 1943, revela casas erguidas sobre chão em terra batida, com paredes de barro, com ventilação deficiente, o que as tornavam úmidas, escuras e propícias ao aparecimento de insetos como moscas e, sobretudo, o barbeiro, causador da doença de Chagas. As cozinhas não possuíam chaminé, deixando o ambiente interno ainda mais enegrecido pela fuligem. As casas não possuíam instalações de água corrente e esgoto, o que levava seus moradores a utilizar "o mato" para banheiro e lavagem das roupas. Além de causar poluição aos leitos do rio, a falta de higiene, associada à má alimentação, segundo o relatório de Knott (citado em Campos, 2006, p.175-176), colocava especialmente as crianças "expostas a disenterias e infecções intestinais". A baixa qualidade das construções, sobretudo em relação ao sistema de distribuição de água, tornava as localidades vulneráveis aos vetores transmissores da malária. 


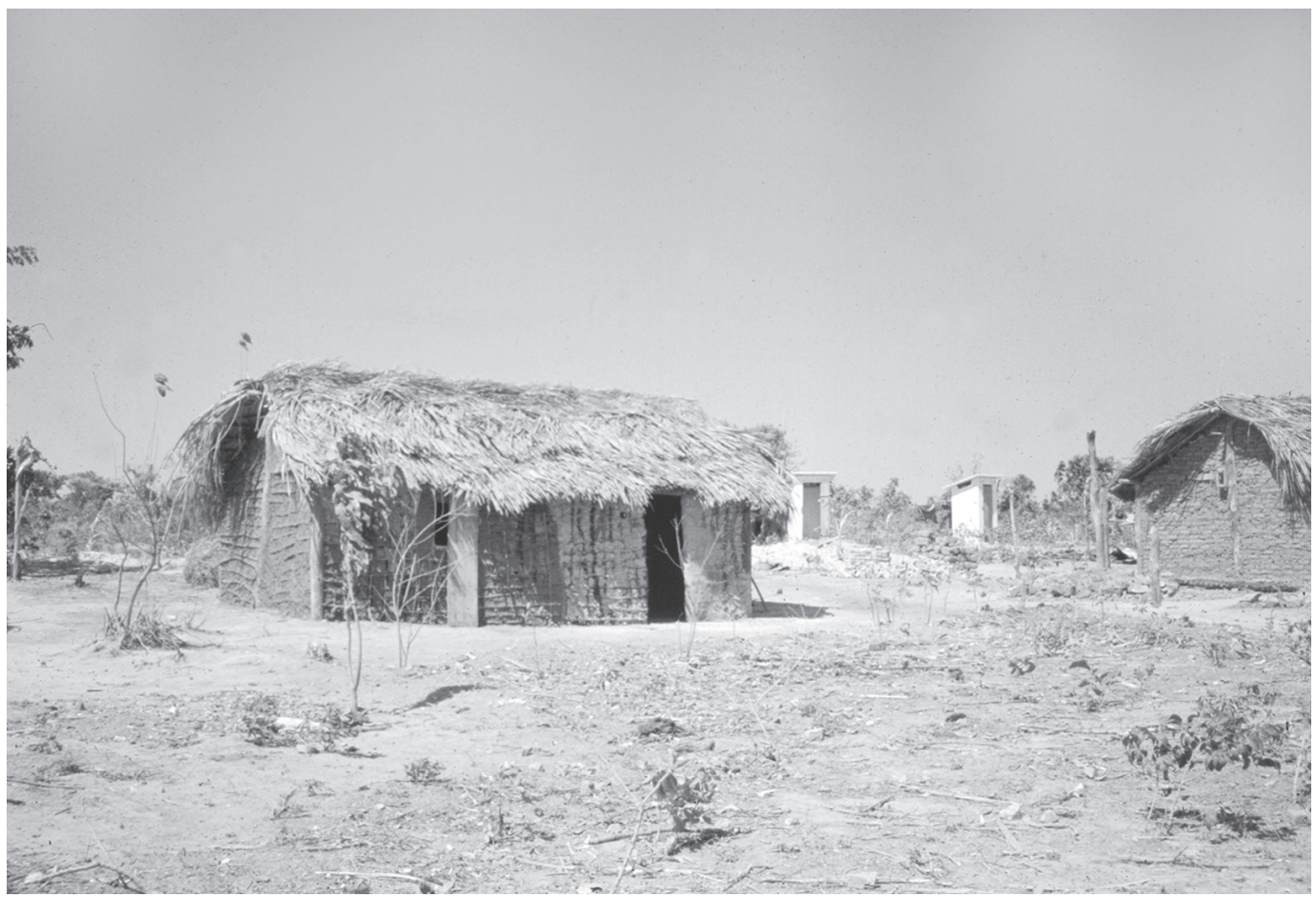

Figura 4: Casa de barro com telhado de sapê e teto de folhas de palmeiras. Realidade encontrada e fotografada por Cynamon em seu trabalho pelo Sesp. Foto apresentada por ele em um dos cursos de formação de inspetores sanitários, s.d. (DSSA/Ensp/Fiocruz)

Como chefe da Seção de Saneamento da Divisão de Orientação Técnica do Sesp, Cynamon realizou diversos projetos por meio do Distrito Sanitário de Governador Valadares, como assistência médica e dentária, imunizações e higiene materna, educação sanitária, coordenando o trabalho de visitadoras domiciliares que orientavam a população sobre higiene doméstica, a semelhança do que havia feito em Colatina. Essa boa atuação de Cynamon estimulou a criação local de "um modelo de gestão autônoma dos serviços e que pudessem suprir a falta de condições técnicas operacionais" (Tércio, 2011, p.37), institucionalizando o Serviço Autônomo de Água e Esgoto (Saae), que, em Governador Valadares, foi aprovado por sua Câmara em 1952. A boa experiência nessa cidade levou a diretoria de engenharia sanitária do Sesp a "incentivar ... outros municípios sob sua jurisdição a criar nas localidades" modelo semelhante (Tércio, 2011, p.37).

Com isso, o Sesp indicava que atuaria, prioritariamente, em projetos de saneamento e abastecimento de água, por meio de suas Unidades Sanitárias (US), além de ações educativas. As US previam, por exemplo, obras de instalação de rede de distribuição de água encanada, com rigoroso controle da qualidade da água doméstica, e rede de esgoto, com instalação de privadas de fossa seca. A instalação de fossa seca precisava contar com o entendimento da população - que não tinha água encanada e nem sistema de esgoto - sobre sua necessidade. Dadas as dificuldades de recebimento de fôrmas metálicas importadas pelo EUA, que acelerariam a instalação das privadas domésticas, Cynamon se empenharia na criação de um 
modelo doméstico que atendesse à demanda planejada pelo Sesp. O engenheiro projetaria, então, um modelo de fossa seca dupla, que ficaria conhecido como fossa tipo Cynamon. As vantagens desse modelo, após críticas iniciais, estariam na facilidade de execução e no baixo custo, além da durabilidade (Tércio, 2011).

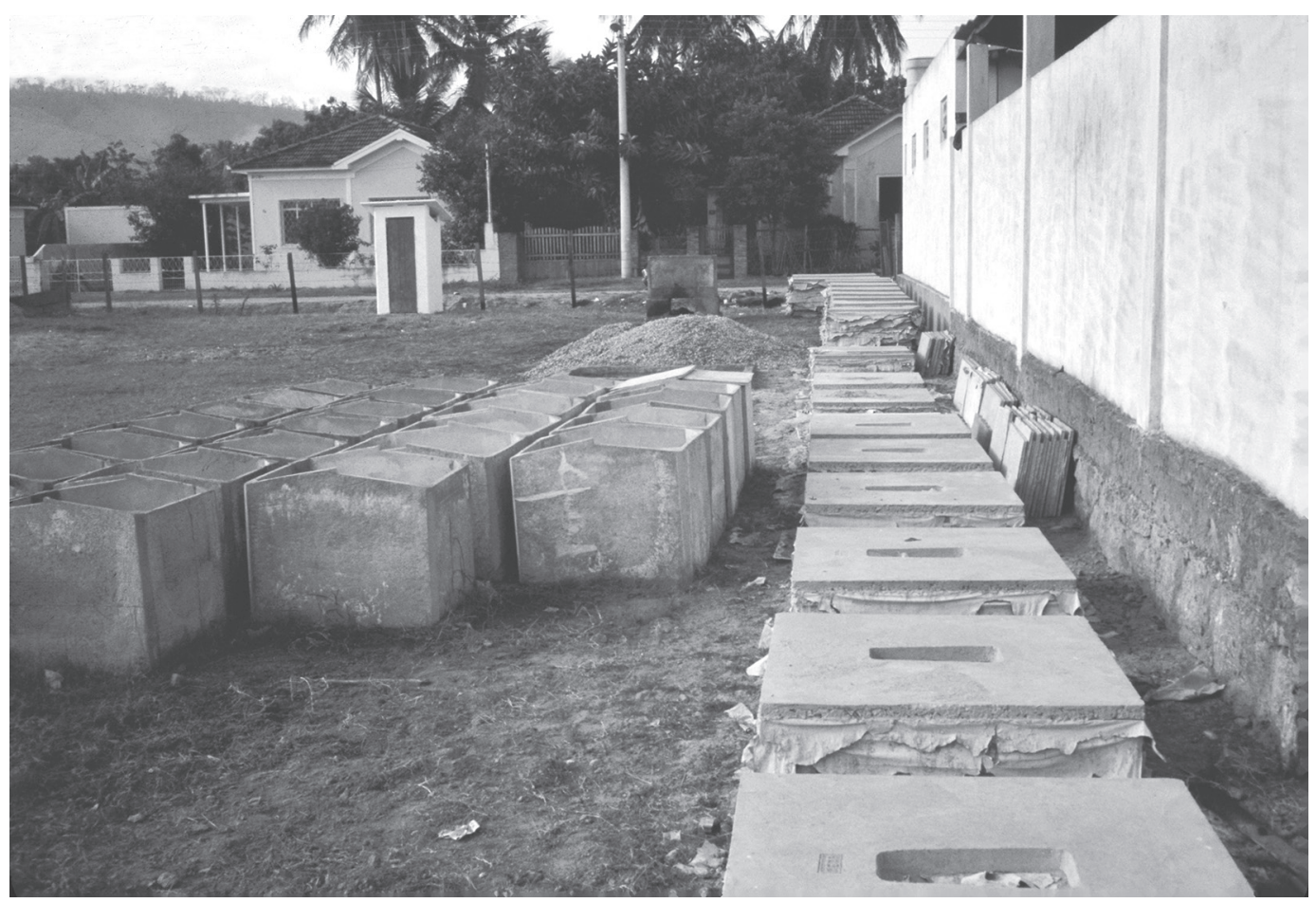

Figura 5: Fossa tipo Cynamon. Foto tirada por Cynamon e apresentada por ele em um dos cursos de formação de inspetores sanitários, s.d. (DSSA/Ensp/Fiocruz)

Em artigo de 1959, o próprio Cynamon escreve sobre a atuação das US e chama a atenção para a conscientização do Sesp acerca da relação entre saneamento e saúde pública, em que soluções apontavam para instalação de redes públicas de esgoto e de abastecimento de água, além da assistência médica (Cynamon, 1959). Tais serviços de saneamento ficavam justamente a cargo das US e sob a supervisão de inspetores de saneamento e engenheiros sanitários. A US, segundo o engenheiro, era "a instituição líder da saúde pública numa determinada localidade, aquela a quem, portanto, cabia dar o tom neste campo, e a quem, apesar da existência de outras instituições oficiais ou particulares locais, cumpria orientar o programa geral de saúde, considerando o saneamento como atividade básica de saúde pública" (Cynamom, 1959, p.541).

De acordo com as Instruções de Serviço, aprovadas em novembro de 1945, cabia ação mais ampla às unidades sanitárias situadas

nas sedes dos municípios e que proviam assistência médica permanente à criança, à gestante e ao adulto, e desenvolviam ainda as seguintes atividades: controle das doenças transmissíveis, enfermagem e educação para a saúde, saneamento básico, coleta de dados de estatística vital. Em áreas selecionadas, acrescentavam-se a essas 
atividades, odontologia sanitária e operação de Dispensário Regional de Tuberculose (citado em Bastos, 1993, p.168).

As atividades das US se organizavam da seguinte forma, segundo Cynamon (1959): na realização de diagnósticos e avaliação permanente sobre as condições locais das áreas a sanear; no empreendimento de ações junto às autoridades, líderes e público de modo geral, com o objetivo de estimular a busca de soluções conjuntas para os problemas básicos locais; na implantação de um programa educativo junto à população acerca das obras de engenharia sanitária, chamando a atenção para o correto uso e conservação das instalações; na orientação e no estímulo à população na execução de soluções individuais de saneamento, enquanto a municipalidade não obtivesse soluções definitivas, como, por exemplo, melhoria da qualidade das fontes de água, proteção e construção de poçoschafarizes e de fossas secas etc. No geral, buscava-se agir nos problemas fundamentais de abastecimento de água, destino de dejetos e melhoria das habitações.

O diagnóstico apontado por Cynamon auxiliava, segundo ele, no conhecimento acerca do tipo de doença associada a diferentes atividades de saneamento. Por exemplo, "a alta incidência do grupo entérico e coeficientes altos de mortalidade infantil requerem trabalho dirigido para a melhoria de abastecimento d'água" (Cynamon, 1959, p.545).

Ao lado dos trabalhos básicos das US, fazia-se um levantamento cartográfico das localidades selecionadas pelos programas de saneamento, que incluía a numeração das habitações; realizavam-se inquéritos sanitários e campanhas para construção de fossas; fazia-se a fiscalização de estabelecimentos de gêneros alimentícios, como mercados, feiras e matadouros, bem como das construções residenciais, visando à entrega do habite-se. Previase, igualmente, dependendo da necessidade local de cada prefeitura, a implementação de planos-diretores e de urbanismo (Cynamon, 1959, p.540).

Os profissionais que compunham as equipes se dividiam entre auxiliar de saneamento, que podia ser recrutado e treinado na própria localidade servida pela US, bastando ter instrução básica e aptidões manuais para lidar com confecção de banheiros e construção de privadas/latrinas. Tais auxiliares recebiam aulas teóricas e estágios práticos, e, dependendo da sua capacidade e aprimoramento nos estudos, eram promovidos a inspetores de saneamento e assumiam atividades de liderança. A tais inspetores era oferecido um período de estudos de um ano na Faculdade de Higiene e Saúde Pública de São Paulo. Por fim, havia o cargo de engenheiro sanitarista, recrutado entre engenheiros civis, que passavam por estágio de um a dois meses sob orientação de um profissional mais antigo. A tais engenheiros também era oferecido uma bolsa de estudos na mesma faculdade paulista (Cynamon, 1959). Recordamos que Cynamon fez semelhante estágio antes de ser efetivado no Sesp, em 1952. Em pouco tempo, ele próprio estaria na função de professor e coordenador de saneamento em Governador Valadares, instruindo os engenheiros a realizar as tarefas de opinar sobre planos de trabalho, supervisionar atividades, avaliar resultados e servir de consultor em assuntos de saneamento para unidades sanitárias locais.

Um dos documentos mais interessantes do acervo, pertencente ao DSSA, diz respeito ao Manual para o guarda sanitário. A publicação, produzida por João Candido Póvoa Filho (s.d.), na gestão de Ernani Braga na direção do Sesp (1944-1959), foi utilizada por Cynamon 
durante sua atuação no Programa do Rio Doce. O manual tinha o objetivo de "ministrar aos guardas sanitários os conhecimentos básicos fundamentais de Higiene e Saneamento que deverão difundir nessa campanha primordial de levar educação sanitária às populações do Vale do Rio Doce" (Póvoa Filho, s.d., Apresentação).

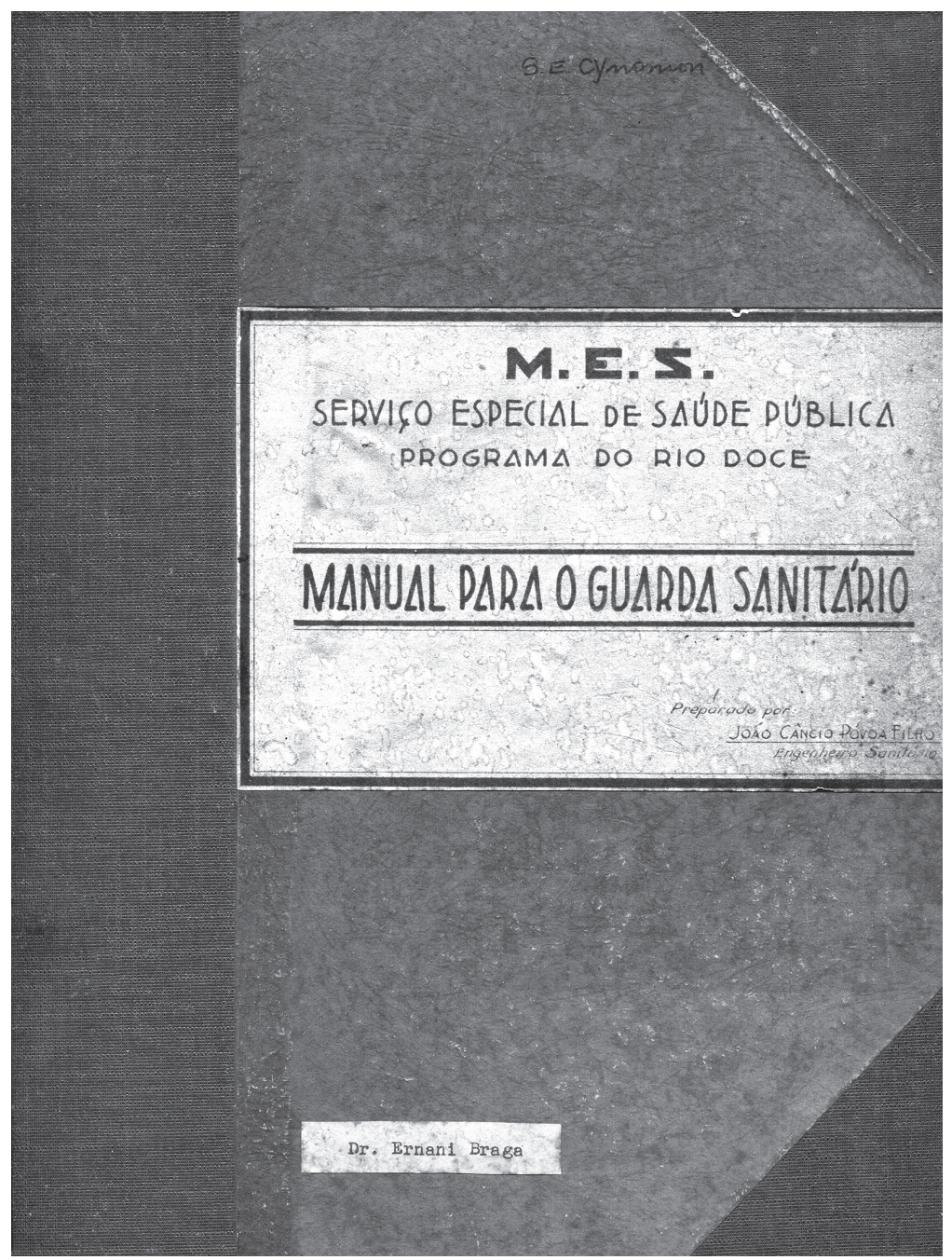

Figura 6: Capa do Manual para o guarda sanitário pertencente a S.E. Cynamon (DSSA/Ensp/Fiocruz)

Os capítulos do manual discorriam sobre noções gerais de higiene e saneamento; doenças transmissíveis (sobretudo malária, febres, disenterias e tuberculose); sistemas de esgoto; abastecimento de água; inspeção do leite; controle de insetos e roedores (mosquitos, moscas, piolhos, pulgas, carrapatos, percevejos, baratas e ratos); coleta de lixo; iluminação, insolação e ventilação de unidades habitacionais; ar e solo; e educação sanitária, entre outros temas. Sobre higiene e saneamento, a publicação afirmava logo na introdução: 
Constituem a 'higiene' os cuidados pessoais que devemos observar com o fim de manter a saúde e evitar as doenças. A higiene requer, apenas, a aplicação de algumas regras de bom senso. A limpeza é o mais importante na higiene pessoal. Constituem o 'saneamento' os cuidados que devemos ter com o meio ambiente, quer dizer, casas, quintais, cidades etc., com o mesmo fim de manter a saúde e evitar as doenças (Póvoa Filho, s.d., p.1; destaques no original).

Pela leitura do manual, percebe-se que o conceito que se tinha de saúde era amplo. As preocupações ali apontadas revelam entendimentos importantes sobre a responsabilidade de se cuidar da saúde da região, assolada por altos índices de malária, especialmente. As estratégias incluíam desde ações no interior das casas, com o envolvimento efetivo da população, por meio dos ensinamentos, da educação e da realização de melhorias em suas habitações e formas de higiene pessoal; até cuidados com a cidade e o meio ambiente, envolvendo poderes locais para o comprometimento com obras de instalação de redes de abastecimento de água, coleta de esgoto e de lixo, iluminação pública etc.

Cynamon faria outros projetos beneficiando Governador Valadares em ação conjunta com o Sesp, como a construção de postos de saúde, e a organização e coordenação de cursos de auxiliar e inspetor de saneamento. Em reportagem de época, chama-se a atenção para a participação de Cynamon em curso de inspetores de saneamento, em que seriam formados 16 jovens.

Para suprir a carência de material didático em português, ${ }^{2}$ foi elaborado um manual de saneamento, cuja primeira edição data de 1960, pela Divisão de Orientação Técnica, de cujo Setor de Saúde do Ambiente Cynamon era chefe. ${ }^{3}$ Após uma introdução apresentando brevemente conceitos acerca de saúde, saneamento e engenharia sanitária, o manual se divide em 11 atividades relativas ao saneamento: abastecimento d'água; destino das águas servidas e dos dejetos; destino do lixo; controle de animais; vetores de doença (subdividido em insetos e roedores); saneamento dos alimentos; da habitação; dos locais de trabalho; das escolas; dos locais de recreação; e saneamento em épocas de emergência ou de calamidades públicas. O manual, distribuído em três volumes, é rico em esquemas e ilustrações, a cargo do inspetor sanitário João Carvalho, abordando cuidados com a higiene; construção de latrinas; sistemas de distribuição de esgotos; construção de poços e estações de tratamento; manuseio dos alimentos; disposição de utensílios domésticos como pias e bebedouros, além de esquemas relacionando vetores e agentes a determinados tipos de doença, em especial doenças intestinais, febre tifoide, butolismo, difteria, tuberculose, entre outras.

Em sua essência, o manual ensina aos alunos que a própria noção de saúde é mais ampla, usando a definição de saúde dada pela OMS: "O mais completo bem-estar físico mental e social e não apenas a ausência de doença e enfermidade", e que saneamento "é o conjunto de medidas visando modificar as condições do meio ambiente com a finalidade de prevenir a doença e promover a saúde" (Brasil, 1964, p.1). Conceitos que Cynamon com certeza apreendeu e soube transmitir a toda uma geração de sanitaristas. 


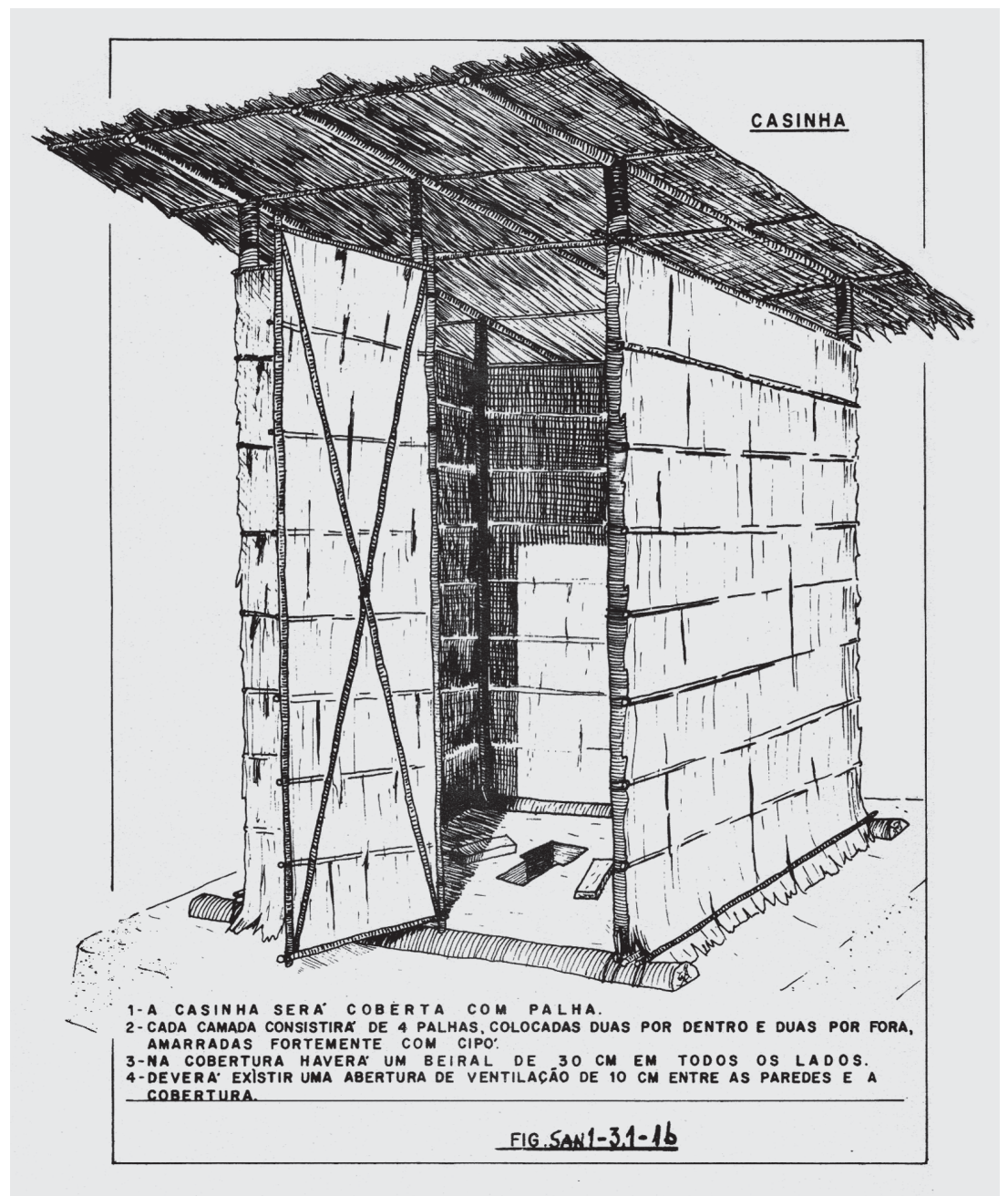

Figura 7: Croqui representativo das privadas antigas (Brasil, 1964, v.2, s.p.)

\section{Considerações finais}

Este texto resulta de reflexões de pesquisas ainda em andamento. Pretendemos trazer para o debate, por meio de fontes documentais primárias, as ações empreendidas entre as décadas de 1940 e 1960, no interior de dois estados brasileiros em relação ao saneamento e à saúde, em cidades localizadas ao longo do rio Doce, recentemente vítima de um dos maiores desastres ambientais da história brasileira, com consequências graves ao meio ambiente e à saúde pública. Procurou-se divulgar, mesmo que brevemente, por meio de acervos relativos ao Fundo Sesp e ao arquivo pessoal de Cynamon, as ações de infraestrutura empreendidas pela agência, especialmente como parte da agenda de expansão da presença do Estado no território brasileiro, em processos inovadores sobre saúde coletiva, medicina social e saneamento no Brasil. 
Com sua experiência, dedicação, competência e capacidade de trabalho, Szachna Eliasz Cynamon procurava contribuir para transformar a realidade social de muitos brasileiros por meio de ações estratégicas em saúde pública e saneamento. Independentemente de grupos e correntes de pensamento, exprimia sua visão missionária, cujas atuações, tanto no campo da formação como das intervenções de melhoria habitacional e de prática de saneamento, representavam uma ideologia de vida. Sua concepção crítica da realidade social e de política pública o transformava em um pesquisador comprometido pragmaticamente com projetos sociais. Desenvolvia tecnologias sociais e de baixo custo, e no processo e contato com a população necessitada via oportunidade de formação continuada e de transformação social. Tinha uma visão de cientista social e compromisso genuíno com a saúde pública, claramente demonstrada por meio da sua rica experiência no vale do rio Doce. Tal análise visa contribuir especificamente para o entendimento acerca da atuação do Serviço Especial de Saúde Pública, e de um de seus mais expoentes funcionários, o engenheiro sanitarista S. Eliasz Cynamon, em pequenos municípios de até cinquenta mil habitantes, por onde se distribui ainda hoje a maioria da população brasileira.

\section{AGRADECIMENTOS}

Este estudo faz parte do projeto "Água, saúde e ambiente na história de projetos de desenvolvimento no Brasil do século XX", coordenado por Dominichi Miranda de Sá, com financiamento da Casa de Oswaldo Cruz (COC) e do Conselho Nacional de Pesquisa e Desenvolvimento (CNPq). Uma versão deste texto foi apresentada no primeiro Congresso Ibero-americano de História Urbana.

\section{NOTAS}

${ }^{1}$ Em reportagem publicada no Estadão, em 14 de janeiro de 2017, a bióloga da Fiocruz, Márcia Chame, confirma a ligação entre o rompimento da barragem em 2015 e o recente surto de febre amarela no vale do rio Doce (Formenti, 14 jan. 2017). Ela chama a atenção para a alteração no meio ambiente da região que estaria causando a morte de macacos e a consequente epidemia em seres humanos. Em outra reportagem, o cientista Renato Pereira de Souza, do Instituto Adolpho Lutz, chama a atenção para a relação da febre amarela com o desequilíbrio ambiental, que estaria trazendo novos elementos à versão urbana da febre, que desde 1942 não tem caso registrado oficialmente no Brasil (Azevedo, Souza, 17 jan. 2017). Segundo as reportagens, as cidades mais atingidas são a de Governador Valadares (MG) e Colatina (ES).

${ }^{2}$ Cynamon possuía "como bíblia" o livro Saneamento urbano e rural, de Ernest W. Steel, que ele consultava a toda hora e usava como material de aula (Cynamon, 3 fev. 2004, fita 1, lado B).

${ }^{3}$ Uma segunda versão, corrigida, foi publicada em 1964. Ambas as edições se encontram no acervo do sanitarista sob a guarda do DSSA/Ensp/Fiocruz.

\section{REFERÊNCIAS}

AZEVEDO, Ana Lucia; SOUZA, Renato Pereira de.

Surto confirma expansão da doença no país. $O$ Globo, p.24. 17 jan. 2017.

BASTOS, Nilo Chaves de Brito.

Sesp-FSESP: evolução histórica, 1941-1991.

Recife: Comunicarte. 1993.

BRASIL.

Ministério da Saúde. Fundação Serviço Especial de Saúde Pública. Manual de saneamento. Rio de Janeiro: Sesp. 2v. 1964.
CAMPOS, André Luiz Vieira.

Políticas internacionais de saúde na Era Vargas: o Serviço Especial de Saúde Pública, 1942-1960. Rio de Janeiro: Editora Fiocruz. 2006.

CYNAMON, Szachna Eliasz.

[Depoimento] Entrevistadores: Cristina Fonseca, Paulo Elian dos Santos. Rio de Janeiro: Departamento de Arquivo e Documentação/ Casa de Oswaldo Cruz/Fiocruz (BR RJCOC 0501). 9 fitas cassete (9h). Depoimento concedido ao Projeto Escola Nacional de Saúde Pública (Ensp): 50 anos de história. 3 fev. 2004. 
CYNAMOM, Szachna Eliasz.

Atividades de saneamento desenvolvidas pelas Unidades Sanitárias do Sesp. Revista do Serviço de Saúde Pública, v.10, n.2, separata. 1959.

FORMENTI, Lígia.

Para bióloga, surto de febre amarela pode ter relação com tragédia de Mariana. Estadão. Disponível em: http://saude.estadao.com.br/ noticias/geral,para-biologa-surto-de-febreamarela-pode-ter-relacao-com-tragedia-demariana,10000100032. Acesso em: 18 jan. 2017. 14 jan. 2017.

FUNASA.

Fundação Nacional de Saúde. 10 anos de saúde pública: "O compromisso do governo é incluir socialmente a população, especialmente os mais carentes". Funasa em Revista, ano 1, n.1, p.16-21. 2004.

HOCHMAN, Gilberto.

A era do saneamento: as bases da política de saúde pública no Brasil. Rio de Janeiro: Hucitec. 2013.

MELO, Carlos Henrique.

Saneamento ambiental na Funasa: da concepção preventivista aos desafios da reforma sanitária. Dissertação (Mestrado em Saúde Pública) Escola Nacional de Saúde Pública Sergio Arouca, Fiocruz, Rio de Janeiro. 2004.

MONTEIRO, Paulo António.

A experiência do Departamento de Engenharia de Saúde Pública (Densp) da Fundação Nacional de
Saúde (Funasa) com vistas à contribuição para o desenvolvimento de uma política de saneamento em Guiné Bissau. Dissertação (Mestrado em Saúde Pública) - Escola Nacional de Saúde Pública Sergio Arouca, Fiocruz, Rio de Janeiro. 2015.

PÓVOA FILHO, João Candido.

Manual para o guarda sanitário. Rio de Janeiro: MES; Sesp; Programa do Rio Doce. s.d.

PRD.

Programa do Rio Doce. Relatório do Serviço Especial de Saúde Pública do segundo trimestre de 1944. Código SP-01-OF.109 (Departamento de Arquivo e Documentação/Casa de Oswaldo Cruz/Fiocruz, Rio de Janeiro). 1944.

SANTOS, Vanessa Sardinha dos.

Acidente em Mariana (MG) e seus impactos ambientais. Disponível em: http:// mundoeducacao.bol.uol.com.br/biologia/ acidente-mariana-mg-seus-impactos-ambientais. htm. Acesso em: 11 jul. 2016. 2015.

SNIS.

Sistema Nacional de Informações sobre Saneamento. Diagnóstico dos Serviços de Água e Esgotos. 2014. Brasília: SNSA/Ministério das Cidades. 2016.

TÉRCIO, Jason.

As aventuras de um sanitarista bandeirante. Rio de Janeiro: Ensp. 2011. 